\title{
Alimento y cuerpo en Sor Juana de la Cruz (1481-1534) y en El libro del conorte
}

\author{
María LUENGO BALBÁS \\ Universidad Complutense de Madrid \\ maria.luengo@colegio-estudio.com
}

\section{RESUMEN}

El presente trabajo realiza un análisis sobre las relaciones entre el cuerpo y el alimento que se presentan en la obra y la biografía de la beata castellana Sor Juana de la Cruz (14811534). La presente investigación nace a partir de dos referentes bibliográficos: por un lado, la obra de Caroline Walker Bynum, Holy Feast and Holy Fast, que analiza las relaciones entre el cuerpo y el alimento en los escritos y las vidas de diferentes visionarias europeas medievales; por otro, partimos del reciente estudio de Sanmartín Bastida, La representación de las místicas: Sor María de Santo Domingo en su contexto europeo, que enmarca a Sor María y a otras religiosas peninsulares dentro de un movimiento visionario europeo. El propósito de nuestro análisis es ampliar la mirada sobre la construcción de la identidad como visionaria de Sor Juana y con ello dilatar el campo de estudio sobre las relaciones entre las comunidades femeninas peninsulares y las del resto de Europa a finales de la Edad Media y comienzos del Renacimiento.

Palabras clave: Sor Juana de la Cruz, visionarias, místicas, comida, cuerpo, performativi$\mathrm{dad} /$ representación, relaciones España y Europa, siglo XV, siglo XVI, sermones.

\begin{abstract}
The present work carries out an analysis about the relationships between body and food that appear in the Spanish beata Sor Juana de la Cruz's (1481-1534) work and biography. The following investigation starts with two bibliographic referents: on the one hand, the work of Caroline Walker Bynum, Holy Feast and Holy Fast, that analyzes the relationships between body and food in the lives and writings of different European medieval visionaries; on the other hand, the recent study of Sanmartín Bastida, La representación de las místicas: Sor María de Santo Domingo en su contexto europeo, which contextualizes Sor María and other Peninsular religious within a European visionary movement. The main purpose of our analysis is to increase our knowledge about the construction of Sor Juana de la Cruz's identity as a visionary in order to expand the field of study on the relationships between the Peninsular female communities and the European ones at the end of the Medieval Ages and the beginning of the Renaissance.

Keywords: Sor Juana de la Cruz, visionaries, mystics, food, body, performativity, relationships Spain and Europe, $15^{\text {th }}$ century, $16^{\text {th }}$ century, sermons.
\end{abstract}


La idea del presente trabajo parte del reciente estudio de Sanmartín Bastida, $L a$ representación de las místicas: Sor María de Santo Domingo en su contexto europeo, obra que enmarca a esta beata y con ella a otras religiosas contemporáneas peninsulares dentro de un contexto religioso europeo que nos permite ampliar la mirada de las biografías y escritos femeninos del momento no como hechos aislados, sino como parte de una mística continental. Uno de los campos de estudio de la mencionada investigación es la aplicación de la teoría de la performatividad ${ }^{1}$ para comprender cómo las diferentes religiosas construyeron su comportamiento sobre el modelo de la visionaria. La contextualización de las visionarias de la Edad Media y el Renacimiento en su marco continental es un campo que ha descuidado la crítica hispánica, que sí ha hecho estudios de conjunto de las religiosas visionarias peninsulares $^{2}$, pero que no ha profundizado en la comparación con sus contemporáneas europeas y las posibles influencias, tanto en su construcción como personajes públicos como en sus escritos.

En la citada obra acerca de Sor María de Santo Domingo se estudian diferentes aspectos repetidos en las visionarias medievales y renacentistas europeas y en algunas religiosas peninsulares como la recurrencia del motivo de la maternidad, el interés por los estados del cuerpo o las relaciones entre el cuerpo y la comida, motivo que aquí nos ocupa. En este trabajo vamos a abordar las relaciones del cuerpo y la comida desde los dos referentes que Sor Juana nos ha dejado: por un lado, el relato hagiográfico que recoge su historia y por otro, la obra escrita de la visionaria: $E l$ libro del conorte. En cuanto a su biografía, nos detendremos en la importancia que en la misma constituyen los extensos ayunos a los que Sor Juana, como muchas visionarias, se sometió a lo largo de su vida. En su texto buscaremos de qué manera es presentado el motivo del alimento en relación con el cuerpo, especialmente, la imagen de Cristo como comida, y las relaciones de esta presentación con otros textos europeos. Con ello buscamos inscribir a Sor Juana dentro de un movimiento religioso femenino del que, como ha demostrado en su estudio Sanmartín, no quedaron excluidas las visionarias peninsulares que siguieron, tanto en su biografía como en sus textos, el que ya era consolidado patrón de la visionaria.

La biografía de esta religiosa, como la de prácticamente todas sus contemporáneas, se encuentra plagada de lugares comunes de los relatos hagiográficos femeninos. Sor Juana de la Cruz (1481-1534) nació en una familia humilde que concertó para ella un matrimonio con un joven noble. Sin embargo Juana Vázquez no aceptó esta unión y abandonó el hogar familiar vestida de caballero ${ }^{3}$, para ingresar en una

\footnotetext{
${ }^{1}$ Sanmartín parte de las teorías de la construcción de la identidad de Judith Butler (1990, 2004) para entender cómo la identidad de la mística o la visionaria se crea a partir de la imitación de unos patrones de comportamiento.

${ }^{2}$ Véase R. Surtz (1995) y A. Muñoz Fernández (1994).

3 Acerca de la repetición de este motivo en los relatos hagiográficos femeninos véase A. Gómez Moreno (2008), pp 148-177.
} 
comunidad religiosa cercana a Cubas, en el arzobispado de Toledo. Sor Juana llegó a ser abadesa del convento de Santa María de la Cruz, donde alcanzó gran popularidad debido a sus arrebatos místicos, que experimentó durante trece años, en los que Dios se manifestaba a través del cuerpo de la religiosa. Estos éxtasis fueron muy famosos, e importantes personalidades de la época, como el Cardenal Cisneros o Carlos V, fueron a visitar a sor Juana cuando se encontraba en este estado de contacto con la divinidad.

Varios fueron los biógrafos que pusieron por escrito su Vida, destacando entre ellos sor María Evangelina, cuya obra fue redactada tras la muerte de Sor Juana, y el Padre Daza (1610). Su vida fue llevada al teatro por varios dramaturgos ${ }^{4}$ entre los que destaca Tirso de Molina con su trilogía La Santa Juana (1613-1614) ${ }^{5}$.

Sor Juana de la Cruz no es una santa reconocida oficialmente por la Iglesia. En el año 1610 se inició en Roma su proceso de beatificación, pero fue frustrado por los censores tanto de El libro del conorte como de la biografia redactada por el Padre Daza, que tachaban su obra de heterodoxa ${ }^{6}$. A pesar de ello, Sor Juana fue tenida por santa tanto por sus contemporáneos como por generaciones posteriores, y en sus biografías se trata su figura como la de una verdadera santa, por lo que, olvidando la realidad histórica, las leyendas que cuentan su vida cumplen perfectamente los objetivos de las narraciones hagiográficas. Precisamente uno de los episodios en que se presenta a esta mujer como un prototipo de santidad femenina es en su etapa de lactancia, durante la cual, según nos dicen sus hagiógrafos, el bebé comenzó a someterse a importantes ayunos ${ }^{7}$ :

Apenas auia nacido (como dizen) quando se començo a manifestar en ella la grandeza de las marauillas de Dios, y en tan tierna edad començo a declararse en ella con notable assombro de las gentes: porque rezien nacida ayunaba los Viernes, mamando solo una vez al dia, que tan temprano como es-

\footnotetext{
${ }^{4}$ Salas Barbadillo (1621); Bernaldo de Quirós (1652); J. Cañizares (1723).

${ }^{5} \mathrm{~T}$. de Molina (1998).
}

${ }^{6}$ Sobre el proceso véase, I. García Andrés (1999), pp. 43-53.

${ }^{7}$ Este episodio enmarcaría a la niña Juana dentro del tópico del puer / senex, lugar común en los relatos hagiográficos que presentan los primeros momentos de la vida de los religiosos como claros indicadores de la posterior perfección de los santos. Este tópico normalmente nos presenta a un niño que se muestra sorprendentemente sabio en los primeros años de la infancia. En este caso la santidad se manifiesta en una temprana abstinencia a la hora de comer. Véase A. Gómez Moreno (2008), pp. 97-114.

El motivo gustaría tanto a sor Juana que ella misma lo reelabora en El libro del conorte donde la Virgen: "(...) Y como ella [Santa Ana] la tomase para darle de mamar y la tomase para darle de mamar y la envolviese, la niña no quería mamar sino una vez al día". I. García Andrés (1999), p. 1147.

El motivo de la renuncia a la lactancia como marca de santidad aparece recogido en docenas de biografías, como la de la italiana del siglo XVII Verónica Giuliani. (R. Bell (1985), p. 58-59) 
to quiso Nuestro Señor dar muestras en su sierua de las grandes abstinencias y ayunos, en que adelante la auia de hazer tan señalada y famosa ${ }^{8}$.

Este elemento del ayuno es uno de los principales episodios de la biografía de la visionaria ${ }^{9}$ que nos permite enmarcarla dentro de un contexto religioso europeo. Fundamental en este campo de estudio resulta la obra de Caroline Walker Bynum, Holy Feast and Holy Fast, donde estudia la concepción del ayuno, de la comida y del cuerpo femenino como forma de alimento en los escritos de algunas mujeres religiosas europeas de la Edad Media, tanto en sus biografías como en sus propias obras $^{10}$. En este estudio Bynum demuestra que el motivo del alimento es un elemento reiterado tanto en las biografías de las religiosas como en sus escritos. La espiritualidad femenina europea, marcada por un ascetismo penitencial, encontró en el ayuno una de las vías para manifestar la imitatio christi. Rescata Bynum diferentes estudios según los cuales el motivo del ayuno se recoge mayoritariamente en las biografías de religiosas mientras que apenas aparece en las de sus coetáneos masculinos, a excepción de las vidas de los ermitaños ${ }^{11}$.

Las biografías de las más destacadas visionarias tanto del sur como del norte de Europa están marcadas por los excesos en los ayunos. Así, en las vidas de importantes místicas medievales como Hildegarda de Bingen, Catalina de Siena, Ángela de Foligno o Margarita de Cortona se narran los prolongados ayunos que se interpretan de diversas maneras que Bynum resume:

What ties these distinctive spiritualities together is the same pattern we find in women's lives, as seen by themselves and by male biographers. Is a threefold pattern: women fast, women feed others, and women eat (but never ordinary food $)^{12}$.

\footnotetext{
${ }^{8}$ Daza (1613), p. 68.
}

${ }^{9}$ Son frecuentes en su biografía descripciones de esta abstinencia durante su vida adulta. Vemos un ejemplo: "Y fueron tantos sus ayunos, que sucedia que no desayunarse en tres días, y hartas vezes se passauan los ocho enteros sin comer ningún bocado". Daza (1613), p. 85 .

${ }^{10}$ En este campo de estudio resulta imprescindible también la obra de R. M. Bell (1985) a la que Bynum hace referencia para iniciar su investigación, pero de la que se aleja en su conclusión de que el comportamiento de abstinencia de estas religiosas podría ser denominado como anorexia nerviosa.

Dentro de este mismo campo de estudio de las relaciones entre alimento y textos femeninos religiosos, véase C. Mazzoni (2005).

${ }^{11}$ Acerca de los estudios estadísticos, véase D. Weinstein y R. Bell (1982) o el de R. Kieckhefer, (1984), el estudio de los dos primeros analiza la vida de 864 santos que vivieron entre 1000 al 1700; sobre los patrones masculinos y femeninos, Vauchez (1981). Véase C. W. Bynum (1987), p. 76.

${ }^{12}$ C. W. Bynum (1987), p. 186. 
En primer lugar, la abstinencia es una marca externa de santidad y por lo tanto una manera de visibilizar la espiritualidad de la religiosa ${ }^{13}$, pues como dice Gilmore en su estudio sobre la construcción de la identidad en las biografías de las visionarias, en ellas "the body becomes evidentiary text"14. Además, señala Bynum que es una forma de poder con la que la visionaria manipula a aquellos que la rodean. Para muchas, esta vía de ascetismo se traduce en un camino de ayuda al necesitado: el ayuno propio es entendido como una forma de alimentar al hambriento, pues la espiritualidad de estas religiosas estaba asociada a las labores de caridad que las mujeres realizaban desde las organizaciones religiosas, especialmente en los países del sur de Europa, donde estas comunidades tenían una actitud más activa, frente a aquellas del norte de Europa, donde se vivía una espiritualidad más contemplativa ${ }^{15}$. En muchos casos, las religiosas se privaban de todo bien terrenal y se entregaban a la ayuda de los más necesitados, conducta que llegaba en muchas ocasiones a truculentos excesos, como la ingesta del pus de los enfermos o la bebida del agua donde los leprosos se habían lavado ${ }^{16}$. En la obra de muchas el ayuno es también un paso que acerca a la visionaria a la contemplación de la divinidad y facilita la unión de esta con Dios. Los largos ayunos a los que se sometían las religiosas eran únicamente perdonados durante la comunión que para muchas, como lo fue para Sor Juana, llegó a ser una práctica diaria ${ }^{17}$.

Como estudia Sanmartín, la configuración de la visionaria se origina en una cadena de imitaciones que van ampliando y modelando el patrón de la mística ${ }^{18}$. Así, cuando nuestra religiosa se erige como una visionaria, el modelo de la mística que rechaza el alimento está ya configurado y ella no solo es descrita por sus hagiógrafos como una mujer destinada a la santidad, como nos señalaba el episodio inicial de la abstinencia de la Juana niña, sino que en su edad adulta continúa construyéndose sobre este modelo con una vida austera de largos periodos de meditación y renuncia de lo terrenal ${ }^{19}$. Sor Juana, al igual que otras religiosas mencionadas, gozó

\footnotetext{
${ }^{13}$ R. Sanmartín (2012), p. 223.

${ }^{14}$ K. Ashley, L. Gilmore, G. Peters. (1994), p. 65.

${ }^{15}$ C. W. Bynum (1987), p. 28.

${ }^{16}$ C. W. Bynum (1987), p. 172.

${ }^{17}$ C.W. Bynum (1987), p. 168. Como señala Sanmartín, la práctica de una comunión diaria era un privilegio concedido a muy pocas personas. Las autoridades religiosas consideraban irreverente la comunión frecuente. En el s. XVI autores como Fray Luis de Granada defienden que la comunión no debe superar la práctica semanal. De hecho, Sor Juana debió modificar su conducta y cambiarla por una comunión espiritual pues se le prohibió tomar el sacramento de forma diaria. Sanmartín (2012), p. 233.

${ }^{18}$ R. Sanmartín (2012), pp. 115-123.

19 También en El libro del conorte encontramos ejemplos en los que se alaba la importancia de que los hombres, mientras se encuentren en el mundo terrenal, no deben dedicarse en exceso a la ingesta de alimentos, pues éstos son entendidos como algo que perjudica la pureza espiritual: “(...) A los buenos y contemplativos les es paraíso y refrigerio muy grande,
} 
del privilegio de una comunión diaria para la que se preparaba con extensos ayunos. Estos son destacados de manera especial al tratar su larga enfermedad, durante la cual se negó a probar cualquier forma de alimento ${ }^{20}$.

Pero, decíamos al comienzo que la relación del alimento y el cuerpo no imita al modelo europeo exclusivamente en el comportamiento vital de Sor Juana. Es también a través del texto de la religiosa, El libro del conorte, donde encontramos importantes lazos que la hermanan con las visionarias europeas. Esta obra es fruto de las revelaciones que Sor Juana vivió a lo largo de trece años, durante los cuales la divinidad se manifestaba a través de su cuerpo. Las compañeras de su comunidad copiaron al dictado aquello que Sor Juana fue transmitiendo y, como fruto de aquella traslación, nos ha llegado El libro del conorte, que recopila setenta y dos sermones en los que se narran eventos del calendario cristiano seguidos de unas sorprendentes celebraciones realizadas en el Cielo en conmemoración de dichos eventos. En estas celebraciones se suele convocar a todos los ángeles y bienaventurados para que asistan a un espectáculo teatral en el que se representa la ocasión que se está recordando. Es en este momento festivo donde la alimentación y el cuerpo se convierten en una metáfora central de la obra, pues todo lo que en la tierra ha sido renuncia y sacrificio en el Cielo debe convertirse en desbordamiento y disfrute que es la manera con la que Cristo premia a los que han sabido tener un comportamiento recto en la tierra ${ }^{21}$.

En numerosos pasajes de la obra leemos como Cristo se preocupa por llenar las mesas del Cielo de muy ricos manjares. En estos fragmentos podemos apreciar el gusto que la beata tiene por detenerse en lo fastuoso y lo exuberante pues es esta una de las características más destacadas de su obra, la de interpolar el sufrimiento en la tierra con el disfrute máximo en el Cielo. Sor Juana se recrea en la descripción de los

porque, ayunando y nunca comiendo sino poco, pueden contemplar y gustar y tener delante de sí presentes todos los manjares y dulcedumbres divinales; y pueden gustar y comer y hartarse y embriagarse de Dios y de sus excelentes gustos y suavidades que son más sabrosos al gusto del ánima que puede ser, al gusto del cuerpo, pan reciente mojado en leche". I. García Andrés (1999) p. 549.

${ }^{20}$ Acerca de las relaciones entre la biografía de las visionarias y la enfermedad véase Petroff (1986), pp. 37-44.

${ }^{21}$ Sirva de ejemplo: "Pues yo, mis amigos, que di y doy la gana de comer a los que viven en el mundo, y se la quito cuando es mi voluntad, quiero ahora y me place que, pues es escrito y lo dejé yo en memoria en aquel evangelio de las beatitudes, que eran bienaventurados los que tienen hambre y sed de la justicia porque ellos serán hartos y abastados en el reino de los cielos, y, por tanto, yo quiero que, pues vosotros tuvisteis hambre y sed y estáis ya en el reino de los cielos, que comáis y os hartéis y embriaguéis y abastéis de todos estos manjares que aquí están. Y que así como él hubo acabado de decir estas palabras, a deshora, les puso santa gana de comer, que comieron todos los manjares y panes y frutas y dulcedumbres que allí en las preciosas mesas estaban”. I. García Andrés (1999) p. 974. La negrita de todos los textos citados en el artículo es nuestra. 
lujosos recipientes de estos alimentos así como en la especificación de diferentes tipos de comidas que se ofrecen a los bienaventurados, de entre los que destacan una nutrida colección de los diversos dulces que allí pueden degustarse. Como vemos en el siguiente fragmento, el Dios que habla por la boca de Juana insiste en la necesidad de disfrutar de todos estos alimentos que pone ante los bienaventurados:

Decidme ahora vosotros, mis amigos, todas estas ofrendas de manjares y frutas y roscas y panes recientes que aquí tenéis puesto, ¿para qué es, si no lo habéis de comer ni gozar ${ }^{22}$ ?

Evidentemente, todos estos alimentos son un símbolo de la divinidad que sacia el apetito de los hombres cuando llegan al Cielo. Las escenas de Dios como una forma de alimento tienen su raíz en la propia naturaleza de la eucaristía, y son especialmente frecuentes a partir del Cantar de los Cantares. Los alimentos son la manifestación de Dios, relación que a veces se presenta de una manera metafórica ${ }^{23} \mathrm{y}$ otras de forma explícita. Dentro de este imaginario de la alimentación festiva nos detenemos ahora sobre la más recurrente escena de comida que se da en El libro del conorte, aquella en la que Cristo se ofrece a sí mismo como manjar para que se deleiten los bienaventurados. La autora se sirve de metáforas en las que de manera tangible Dios es un alimento para los comensales. Estas imágenes que utiliza la religiosa no son patrimonio exclusivo de la misma, sino que proceden de una larga tradición de lo que Bynum denomina el banquete sagrado. La estudiosa americana recoge la tradición de los extremos sacrificios que vivían estas visionarias, a la par que destaca cómo en los escritos místicos las metáforas de la comida como una forma de estar en contacto con la divinidad son comunes y repetidas y en algunos casos, como para Hadewijch, Beatriz de Nazaret, Catalina de Siena o Catalina de Génova, Matilde de Magdeburgo y Margery Kempe, son imágenes centrales de sus obras $^{24}$.

22 I. García Andrés (1999), p. 973.

${ }^{23}$ En ocasiones en el texto de Sor Juana se recurre a la imagen de los componentes de la eucaristía, pan y vino, pero normalmente la autora se recrea en la descripción de otros ricos alimentos. Estas imágenes configuran el Cielo de la celebración y el disfrute que imagina sor Juana. La autora contrasta las imágenes del dolor cristiano con las imágenes de la alegría y la fiesta, de manera que siempre parece quedar en el lector de la obra el poso de estas últimas por encima del de aquéllas. "(...) que entonces fueron todos los santos y santas frutas cuajadas y sazonadas para comer, cuando con sus ejemplos y doctrinas hicieron tan gran fruto que todas la Santa Fe Católica dejaron harta y abastada de buenas vidas y obras, para que todos podamos aprovechar a nos y a otros con ella. Porque, aunque las flores son cosa que dan buen olor y buen parecer, no son cosas que puedan comer ni dar hartura a nadie como hace la fruta, cuando está cuajada y sazonada, que cualquiera la puede comer y cumplir su necesidad”. I. García Andrés, (1999) p. 405.

${ }^{24}$ C. W. Bynum (1987), pp. 150-186. 
De todas las formas de alimento que se presentan en El libro del conorte la que sigue es sin duda la que más parece gustar a Sor Juana. En ella Jesús abre su sagrado costado del que manan en unas ocasiones los más dulces manjares y en otras deliciosos licores:

\begin{abstract}
-Ahora, mis amigos, yo os hartaré y os recrearé, que escrito es que 'en mí son hallados pastos, y holganza y deleite y abastamiento'.

Y diciendo estas palabras, a deshora le abrió la llaga de su sagrado costado y le manaba de él un caño de agua muy clara y olorosa; y, por semejante, caía en todos los cálices y tazas, y aguaba el vino y templábalo. Y de las manos de la siniestra le manaba otro licor muy precioso y oloroso; y de las llagas de los pies le salían muchedumbre de manjares. Y luego voló en alto, y púsose sobre las mesas. Y a deshora salieron de todas las llagas y azotes que padeció en su sagrado cuerpo, muchedumbre de panes $\mathrm{y}$ roscas muy recientes y dulces y sabrosas ${ }^{25}$.

(...) En especial, de su precioso costado manaba vino y agua, y de su muy santa cabeza y manos y pies manaban y procedían muy blanco y hermoso pan, hecho a manera de panecicos y rosquitas de azúcar ${ }^{26}$.
\end{abstract}

Ambos pasajes son representativos de un sinfín de ellos que se recogen en la obra de Sor Juana. Esta imagen, que es el centro de la imaginería de la alimentación en la obra de la religiosa toledana, resuena en algunos de los textos de las visionarias del Medievo y del comienzo del Renacimiento, como por ejemplo en el Diálogo de Catalina de Siena, obra con la que Sor Juana tiene diversas concomitancias. En ella Cristo le ofrece a la religiosa en una de sus visiones: "Bebe, hija, de mi costado $^{27 \%}$. La imagen de Cristo alimentando a la visionaria o al sediento mediante su costado es interpretada en muchas ocasiones como una escena de maternidad, así se recoge en una carta del confesor de Catalina de Siena en la que cuenta uno de los relatos que le comunicó la religiosa, quien expresa que Cristo se comportó como una madre con su hijo predilecto al que muestra su seno cuando le enseñó su sagrado costado y que, como consecuencia, ella lloró intensamente deseando poner su boca sobre su sagrada herida ${ }^{28}$, comparación que establece Sor Juana en numerosos episodios de su obra ${ }^{29}$. Este símil de Cristo con una madre que alimenta a su hijo es

\footnotetext{
${ }^{25}$ I. García Andrés (1999), p. 343.

${ }^{26}$ I. García Andrés (1999), p. 873.

${ }^{27}$ C. W. Bynum (1987), p. 172.

${ }^{28}$ C.W. Bynum (1987), p. 173.
}

29 "Y dijo el Señor que como él acabó de decir estas palabras, a deshora, llegaron todos los bienaventurados, y uno tomaba la una mano y otro otra y un pie y el otro pie, y cada uno de los otros tomaba una llaga de las espinas de su sagrada cabeza y de las llagas de los azotes de su sagrado cuerpo, y ponían las bocas en todas aquellas sagradas llagas, $y$ que así manaban dulcedumbres y manjares y bebidas y licores de ellas en tanta manera 
un común denominador tanto de la obra de Sor Juana como la de otras religiosas del continente $^{30}$. La imagen de Cristo nutriendo con la sangre que mana de su costado al igual que otras escenas de lactancia se repite en la obra de muchas visionarias ${ }^{31} \mathrm{y}$ en El libro del conorte son numerosos los pasajes en los que la religiosa se recrea en la maternidad ${ }^{32}$. En estas metáforas de lactancia tiene un papel indiscutible la Virgen. Tanto en las obras de estas visionarias ${ }^{33}$ como en los cuadros que defienden la doble intercesión ${ }^{34}$ se nos recuerda que fue María quien alimentó a Cristo ${ }^{35}$ y por tanto es a ella a quien debe su existencia y a quien todos los cristianos deben su redención. Así Sor Juana en numerosos pasajes recuerda episodios de maternidad de la Virgen:

(...) tomaba sus virginales tetas y mamaba y hacia jueguecitos con señas hacia los Reyes ${ }^{36}$.

(...) hubo compasión de su dulce madre, y empezóle a asir de sus virginales tetas y a sacárselas como que quería mamar, y empezó a llamarla con una voz muy tierna y compasión viva, así como niño necesitado,

que todos comían y se hartaban con gran dulcedumbre, como los niños cuando están mamando y les viene su madre muy abundosamente la leche en tanto que los niños no paladean, mas abren las bocas y tragan la leche muy suavemente, en tanto que sus madres no sienten si maman ni si no". I. García Andrés (1999) p. 1300.

${ }^{30}$ Recoge en su estudio C. W. Bynum algunos ejemplos artísticos de la época en los que Cristo es pintado con un seno que da de mamar, como aquél en el que la Virgen bebe del pecho de Cristo mientras lo sostiene en sus brazos. Bynum (1987) p. 272.

${ }^{31}$ Acerca de las escenas de maternidad en textos de visionarias véase el capítulo "La maternidad y el deseo", Sanmartín (2012), pp. 123-164.

${ }^{32}$ Sirva de ejemplo: "Y por semejante, dijo el Señor, mandó llamar a los que mamaban las tetas de sus madres cuando él entró en Jerusalén, los cuales dejaban de mamar y alzaban las cabezas hacia él abriendo sus voces, por miraglo y maravilla, para le loar y ensalzar". I. García Andrés (1999), p. 582.

${ }^{33}$ Acerca de la importancia del seno de la Virgen en relación con las visionarias: Ed. C. Hanser Verlag (1994).

${ }^{34}$ La siguiente referencia que aparece en El libro del conorte, nos recuerda a estos cuadros en los que mientras Cristo enseña su costado a Dios, la Virgen le muestra su pecho para recordar su papel activo en la intercesión: "Y llorando muy dolorosamente, y ella lo envolvió y curó derramando muchas lágrimas y le halagaba dándole de mamar. Y que él dejaba de mamar, lloraba y sollozaba y ponía las manos y las alzaba hacia el cielo, rogando al Padre celestial, ofreciéndole su llaga y su dolor (...)” (p. 293).

${ }^{35}$ Debemos recordar también la iconografía que nos presenta a la Virgen dando de mamar a San Bernardo donde se presenta la curiosa situación de verse en ocasiones a la virgen amamantando a un mismo tiempo a San Bernardo y a su hijo. M. Yalom (1997), p. 40.

${ }^{36}$ I. García Andrés (1999), p. 314. 
diciéndole con gemido "mamá, mamá, mamá". Y así con este llanto, tornó el mismo Salvador a su gloriosa madre ${ }^{37}$.

Sendos pasajes nos pueden recordar a los de otras visionarias, como los del grupo de místicas alemanas que surge en el s. XIII, entre las que se desarrolló una importante imaginería que realzaba el factor sagrado del seno de la Virgen amamantando al hijo de Dios ${ }^{38}$. Entre ellas destaca Matilde de Magdeburgo ${ }^{39}$ en cuya obra, Luz divina que ilumina los corazones, esta imagen es un motivo muy repetido ${ }^{40}$.

Como hemos visto, las relaciones entre el cuerpo y el alimento representan un intrincado camino en la construcción de Sor Juana como visionaria. Si la beata defiende la vida de abstinencia alimenticia en la tierra, después nos presenta un Cielo en el que los bienaventurados se empachan con diferentes alimentos que Jesús les proporciona. Por tanto, en las escenas de alimentación contamos con una persona que recibe el alimento y otra que se encarga de dar de comer a los hambrientos. Jesús da de comer a los necesitados de la misma forma que la Virgen le dio de comer a él, paralelismo que establece la misma Sor Juana y que se repite en muchas de las visionarias medievales y renacentistas. Son cuantiosos los escritos en los que se rechaza la comida ordinaria para atribuir un increíble poder al alimento eucarísti$\mathrm{co}^{41}$. Y, en el caso de Sor Juana donde el alimento es leído como un premio que se entrega a los bienaventurados, se refuerza la idea de que la penitencia en el mundo será compensada por el Salvador en el Cielo con exquisitos manjares.

Como señala Bynum, esta imagen de Cristo como una forma de alimento es un denominador común en las obras de estas visionarias que será recreada en cada

\footnotetext{
${ }^{37}$ I. García Andrés (1999) p. 386.

${ }^{38}$ Ed. C. Hanser Verlag, (1994).

${ }^{39}$ Esta religiosa nació a comienzos del s. XIII (hacia 1207-1282). Durante gran parte de su vida fue beguina en Magdeburg hasta que ingresó en el convento de Helfta. A lo largo de treinta años escribió el libro Luz Divina que ilumina los corazones donde cuenta sus experiencias de unión con Dios. Como explica D. Gutiérres en la introducción a la obra, la mística escribió su obra en bajo-alemán, por lo que se convirtió en una de las primeras autoras en lengua vernácula. M. Magdeburgo (2004), p. 22. La obra original escrita en bajo-alemán está perdida, pero se hizo una traducción al latín hacia finales del s. XIII, de la que falta el último libro que constituía la obra original, que fue difundida en los círculos dominicos, -no cuento con datos concretos de su difusión en la Península-; entre el año 1343 y 1345 se hizo otra traducción de la obra al alemán. E. Reinhardt (2007), p. 234.

40 “(...) Igualmente admiré sus senos incorruptos desbordantes de leche meliflua, que destilaban para honor del Padre por amor al hombre; sin duda alguna es la más perfecta de las criaturas", M. Magdeburgo (2004), p. 89. Realicé una comparación entre ambas en una ponencia expuesta en el II Simposio de Traslaciones celebrado en Granada en noviembre de 2010 que llevaba por título "La concepción del cuerpo en la obra de Sor Juana de la Cruz".

${ }^{41}$ R. Sanmartín (2012), p. 187.
} 
mujer con una resonancia personal ${ }^{42}$. Quizá, el elemento que más individualiza la imaginería de nuestra religiosa es ese carácter festivo y alegre donde la abundancia de los alimentos divinos está representada mediante verdaderos alimentos terrenales, deliciosos manjares a los que ella misma pudo tener acceso al trabajar como cocinera en el convento ${ }^{43}$ : dulces, rosquillas, panecillos recién hechos, licores... ${ }^{44}$ que son servidos sobre una rica utilería de cuencos, tazas doradas y finos manteles que distancian a nuestra religiosa de otras como Hadewijch o Catalina de Siena que presentan unos banquetes donde el acto de comer es más austero.

Hemos visto que tanto en su biografía como en su escrito Sor Juana imita a un modelo de visionaria para el que la comida supone un elemento de vital importancia. Para este modelo de mujer, como para nuestra religiosa, la renuncia al alimento es un instrumento que refuerza su identidad y que la acerca a la divinidad. El ayuno en la tierra es un aplazamiento del banquete que será servido en el Cielo. Por tanto, el motivo del alimento es uno de los aspectos que nos ayuda a ampliar la mirada sobre religiosas peninsulares como Juana y que nos permite buscar concomitancias entre estas y las místicas y visionarias europeas medievales y renacentistas.

\section{Obras citadas}

Ashley, Kathleen, GILMORE, Leigh, PeTERS, Gerald, (Eds.): Autobiography and postmodernism, Amherst, The University of Massachusetts Press, 1994.

BASTIDA SANMARTín, Rebeca: La representación de las místicas: Sor María de Santo Domingo en su contexto europeo, Santander, Real Sociedad Menéndez Pelayo, 2012.

Bell, Rudolph M.: Holy Anorexia, Chicago, The University of Chicago Press, 1985.

BERnAldo DE Quirós, Francisco: La luna de la Sagra y Vida de Santa Juana de la Cruz, Madrid, 1664.

${ }^{42}$ C. W. Bynum (1987), p. 186.

${ }^{43}$ R. Sanmartín (2012), p. 221.

${ }^{44}$ El conocimiento detallado de estos dulces y licores podría proceder de sus años de trabajo en la cocina, tarea que desempeñó Sor Juana en su primera etapa como religiosa. Aunque normalmente los recetarios conventuales se ocupan de platos ordinarios, mientras que las comidas más refinadas y las especialidades reposteras quedan recogidas en obras que pertenecen a la corte: "No hay que olvidar que muchos monasterios y conventos, sobre todo los femeninos, eran famosos por sus especialidades de repostería, confitería y conservería, destinadas a obsequiar a sus benefactores o a la venta, como ayuda a sus medios de subsistencia”. M. A. Pérez Samper (2012), p. 47; por ello no sería extraño pensar que Juana conoció en primera persona la forma de confeccionar estos dulces. 
ButLer, Judith: Gender Truoble: Feminism and the Subversion of Identity, New York, Routledge, 1990.

- Bodies that Matter. On the Discursive Limits of "Sex", New York, Routledge, 1993. :Undoing Gender, New York, Routledge, 2004.

BYNUM WALKER, Caroline: Jesus as mother: studies in the spirituality of the High Middle Ages, London, University of Carolina Press, 1984.

—-Holy Feast and Holy Fast: The religious significance of food to medieval women, Berkeley, University of California Press, 1987.

CAÑIZARes, José de: El Prodigio de la Sagra: sor Juana de la Cruz. Comedia nueva en verso y tres jornadas, Madrid, 1723.

CORTÉS TIMONER, María del Mar: Sor Juana de la Cruz (1481-1534), Madrid, Ediciones del Orto, 2004.

DAZA, Antonio: Historia, vida y milagros, extasis y reuelaciones de la bienauenturada virgen Sor Iuana de la Cruz, Madrid, 1613.

GARCÍA ANDRÉS, Inocencio (Ed).: El Conhorte: Sermones de una mujer santa, Madrid, Universidad Pontificia de Salamanca y Fundación Universitaria Española, 1999.

GÓMEZ Moreno, Ángel: Claves hagiográficas de la literatura española (del Cantar de mio Cid a Cervantes), Madrid, Iberoamericana Editorial Vervuert, 2008.

HANSER VerlaG, Carl (Ed.): Maria Jungfrau, Mutter, Herrschein Wien, Klaus Schreiner, 1994.

KIECKHEFER, Richard: Unique Souls: Fourteenth-Century Saints and Their Religious Milieu, Chicago, University of Chicago Press, 1984.

Magdeburgo, Matilde de: Luz divina que ilumina los corazones, Burgos, Monte Carmelo, 2004.

MAZZONI, Cristina: The women in God's kithchen: cooking, eating and spiritual writing, New York - London, Continuum, 2005.

MolinA, Tirso de: La santa Juana, Kassel, Reichenberger, 1988.

MUÑOZ FERNÁNDEZ, Ángela: Beatas y santas neocastellanas: ambivalencia de la religión y políticas de poder (s. XIV-ZVII), Madrid, Dirección General de la Mujer / Instituto de Investigaciones feministas de la Universidad Complutense, 1994.

PETROFF, Elizabeth Alvilda: Women's Visionary Literature, New York / Oxford, Oxford University Press, 1986.

- Body and Soul: Essays on Medieval Women and Misticism, New York, Oxford University Press, 1994.

PÉREZ SAMPER, María de los Ángeles: "Recetarios manuscritos de la España moderna", Cincinnati, Cincinnati Romance Review 33 (2012) pp. 27-58.

REINHARDT, Elisabeth: "La antropología de Mectildis de Magdeburgo (s. XIII), Anuario de Historia de la Iglesia, vol. XVI, Pamplona, Universidad de Navarra: 231-244, 2007. 
Salas Barbadillo, A. J.: Los Triunfos de la Beata Soror Juana de la Cruz, Madrid, 1621.

SURTZ, Ronald: La guitarra de Dios, Handcover, University of Pennsylvania Press, 1990.

:Writing Women in Late Medieval Spain: The Mothers of Saint Theresa of Avila, Philadelphia, University Press of Philadelphia, 1995.

VAuchez, André: La Sainteté en Occident aux derniers siècles du Moyen Age d'après les procès de canonisation et les documents hagiographiques, Roma, Ecole de Rome, 1981.

YALOM, Marilyn: The history of the breast, New York, Knopf, 1997.

WeInSteIn, Donald y BeLL, Rudolph M.: Saints and Society: The Two Worlds of Western Christendom, 1000-1700: Chicago, University of Chicago Press, 1982. 